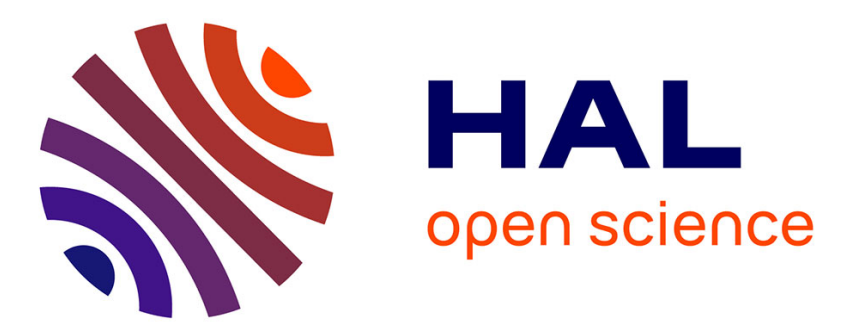

\title{
Investigations on the Fatigue Crack Propagation Threshold in Very High Cycle Fatigue
}

\author{
Chong Wang, Danièle Wagner, Claude Bathias
}

\section{To cite this version:}

Chong Wang, Danièle Wagner, Claude Bathias. Investigations on the Fatigue Crack Propagation Threshold in Very High Cycle Fatigue. Advanced Materials Research, 2014, Melbourne, Australia. pp.357-362, 10.4028/www.scientific.net/AMR.891-892.357 . hal-01421694

\section{HAL Id: hal-01421694 \\ https://hal.parisnanterre.fr/hal-01421694}

Submitted on 18 Jan 2018

HAL is a multi-disciplinary open access archive for the deposit and dissemination of scientific research documents, whether they are published or not. The documents may come from teaching and research institutions in France or abroad, or from public or private research centers.
L'archive ouverte pluridisciplinaire HAL, est destinée au dépôt et à la diffusion de documents scientifiques de niveau recherche, publiés ou non, émanant des établissements d'enseignement et de recherche français ou étrangers, des laboratoires publics ou privés. 


\title{
Investigations on the fatigue crack propagation threshold in Very High Cycle Fatigue
}

\author{
Chong WANG ${ }^{1, a}$, Danièle WAGNER ${ }^{2, b *}$, Claude BATHIAS ${ }^{3, c}$ \\ 1,2,3, University Paris Ouest , LEME Laboratory, \\ 50, rue de Sèvres - 92410 VILLE D'AVRAY - France \\ a.wangchongscu@163.com, ${ }^{\mathrm{b}}$ daniele.wagner@u-paris10.fr \\ c,claude.bathias@u-paris10.fr
}

Keywords: Very high cycle fatigue, fatigue crack initiation, thermal investigation, threshold of fatigue crack propagation, Microplasticity.

\begin{abstract}
Paris's law of fatigue crack propagation rate is well applied in the defect-tolerance fatigue approach. When carry out same approach in the very high cycle fatigue domain, the understanding of mechanism about fatigue crack propagation threshold which is obviously important, is helped. In the present work here, the fatigue crack propagation threshold of a surface crack for an Armco iron loaded in the VHCF regime was investigated by a new approach which combines the fracture surface analysis and the temperature recording on the surface during the test by an infra-red camera. The experiments were carried out on a sheet specimen under a $20 \mathrm{kHz}$ ultrasonic frequency loading with IR images registration. Three stages of fatigue crack were identified with different mechanisms. It is found that the transition between initiation and crack propagation corresponds to the intrinsic fatigue threshold. It takes more than $99 \%$ of the gigacycle fatigue life to achieve this transition size.
\end{abstract}

\section{Introduction}

Whatever the fatigue domain, the fatigue crack mechanism consists of an initiation crack stage (stage I) and a propagation stage (stage II). In the Very High Cycle Fatigue domain (VHCF), the fatigue crack initiates either on the specimen surface, either inside the specimen when the material presents metallurgical inhomogeneities (inclusions...). For materials without inclusions, the first damage events in the stage I are due to the occurrence of Slips Marks (SM) on the specimen surface $[1,2]$ whatever the crystal lattice (bcc or fcc). At the beginning of the long crack propagation, well defined striations occurs (stage II). When the crack initiation site is interior, this leads to the formation of a "fish eye" on the fracture surface. In almost all cases, the fish eye appears circular with a dark area where the crack initiation site is located. Controversies exist on the mechanism leading to initiation [1, 3-5]. In both kinds of initiation site, more than $99 \%$ of the total life is devoted to the crack initiation [6,7]. The crack propagation is less than $1 \%$ of the total life. The transition from the stage I to the stage II (initiation to propagation) corresponds to the threshold corner in the Paris Hertzberg's law [8]. Previous results [7] have found that the $\Delta \mathrm{K}$ at this corner in a fish eye initiation is almost constant and equal to $4 \mathrm{MPa} \sqrt{\mathrm{m}}$ for bearing steels with a martensitic microstructure. However, the same statistical analysis for the surface initiation in the VHCF domain is less studied.

In this article, the $\Delta \mathrm{K}$ at the transition between the initiation stage and the propagation stage was measured on a material without inclusion (Armco iron) where the crack initiates on the specimen surface from the SM. For this purpose, tests were performed in the VHCF domain at $20 \mathrm{kHz}$ with the temperature recording on the specimen surface by an infra-red camera. Post mortem fractographic observations were done with a Scanning Electron Microscope, whose results are in very good agreement with the temperature field. 


\section{Materials}

The studied material is a polycrystalline $\alpha$ iron whose chemical composition is given in Table1. The carbon content is $80 \mathrm{ppm}$. The microstructure is ferrite with equiaxe grains. The ferrite grain size is included in 10 to $40 \mu \mathrm{m}$. No specific orientation was observed by EBSD. Yield Stress is $240 \mathrm{MPa}$.

Table 1: Chemical composition of studied material (wt\%)

\begin{tabular}{|c|c|c|c|c|c|c|c|c|c|c|}
\hline $\mathrm{C}$ & $\mathrm{P}$ & $\mathrm{Si}$ & $\mathrm{Mn}$ & $\mathrm{S}$ & $\mathrm{Cr}$ & $\mathrm{Ni}$ & $\mathrm{Mo}$ & $\mathrm{Cu}$ & $\mathrm{Sn}$ & $\mathrm{Fe}$ \\
\hline 0.008 & 0.007 & 0.005 & 0.048 & 0.003 & 0.015 & 0.014 & 0.009 & 0.001 & 0.002 & Balance \\
\hline
\end{tabular}

\section{Experimental procedure}

Tests were performed on a piezoelectric fatigue machine designed by $\mathrm{C}$. Bathias and co-workers [9].

For the reason of surface observation condition by IR camera, a new design of $1 \mathrm{~mm}$ flat specimen (Fig.1) was used to carry out fatigue tests. Specimen, special attachment and piezoelectric fatigue machine constituted the resonance system working at $20 \mathrm{kHz}$. The cyclic loading is tensioncompression $\left(R_{\sigma}=-1\right)$. Ten specimens were tested with a stress amplitude comprised between 107 $\mathrm{MPa}$ and $222 \mathrm{MPa}$ leading to a fatigue life from $5.6 \times 10^{5}$ cycles to $2.8 \times 10^{8}$ cycles.

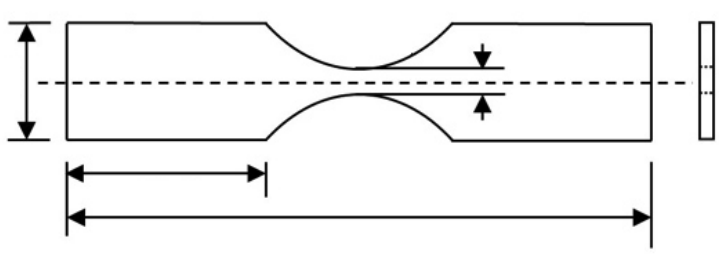

Fig. 1: Design of flat specimen

A CEDIP Orion infrared camera was used to record the temperature evolution during some tests. The frequency of the camera was $50 \mathrm{~Hz}$ and the aperture time was $100 \mu \mathrm{s}$. Before testing, both side surface of the flat specimen were electrolytic polished and etched. One side surface of the flat specimen was painted in black color to have the surface emissivity close to 1 .

\section{Results and discussion}

Fracture surface analysis. The fracture surface and the polished specimen surface (where the temperature was recorded) were observed under Scanning Electron Microscope. Figs 2a and $\mathrm{b}$ are the fracture surface of the specimen tested at $\sigma_{\mathrm{a}}=178 \mathrm{MPa}$ and $\mathrm{N}_{\mathrm{f}}=3.255 \times 10^{7}$ cycles. But, for all tests, the results were qualitatively the same. Until the point 5 , the fracture surface is flat and correspond to the plane strain fatigue crack. Between the point 5 and 6 , the fracture surface presents shear lips.

The enlargement of the plane strain fatigue crack (Fig. 3a) shows two main zones separated by the line at the point 3 . The crack initiation site is located in the lower edge. In the stage I (Fig. 3b), the trace of the grains in which Slips Marks assimilated at Persistant Slips Bands (PSB) have appeared as previously published $[1,10]$ are visible. After the point 3 , the stage II of long crack propagation begins with striations. At the beginning of this stage II, the striations are not well established (Fig. $3 \mathrm{c}$ ), whereas after the point 4 (and the corresponding line), the striations are well defined (Fig. $3 \mathrm{~d}$ ). The lower side of the specimen has been more particularly observed (Figs 4a, b, c). Fig. 4c is the picture around the point 3 where a change in fracture surface can be observed. After the point 3 , 
striations are present and correspond to the long crack propagation as previously reported. Between the specimen corner and the point 3, another fracture surface change appears at the point 1 . On the right side of the photo, the grain traces are clearly observed, whereas after the point 1 (Figure 4b), the fracture surface appearance change, change which is attributed to the transition from the crack initiation stage (stage I) to a transition zone. The trace of the grains vanishes.

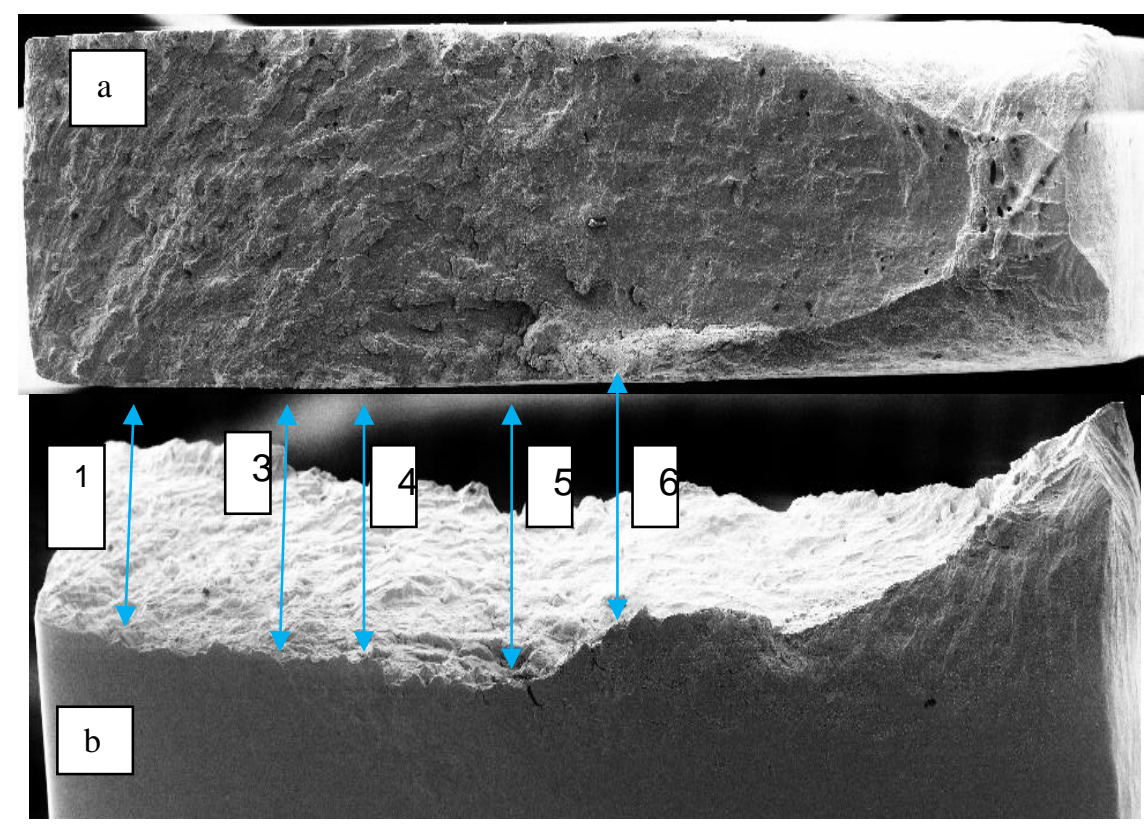

Figure 2a)b): SEM observations of the whole fracture and polished surface

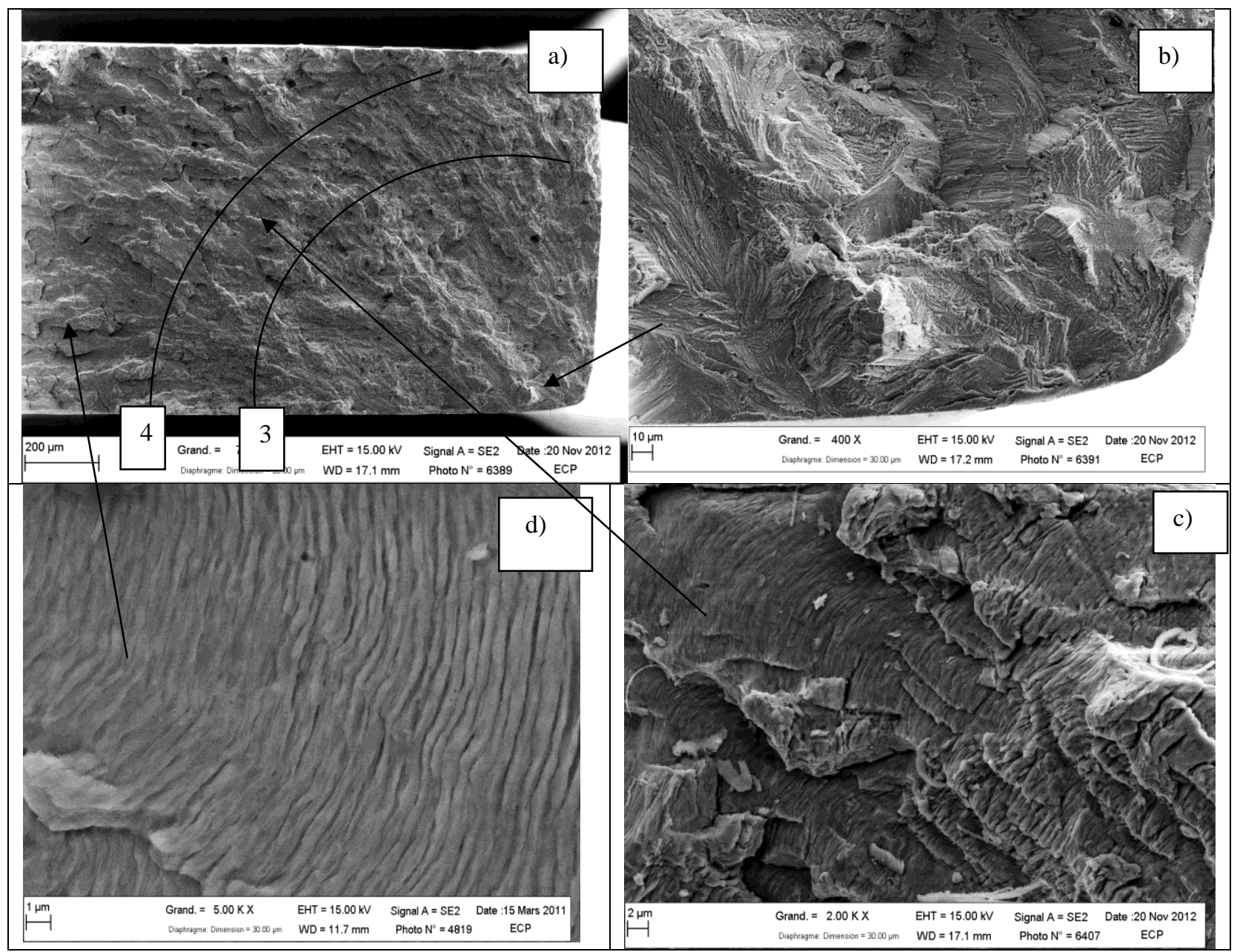

Figure 3 a)b)c)d) : SEM plane strain fatigue crack surface and details of each stage 


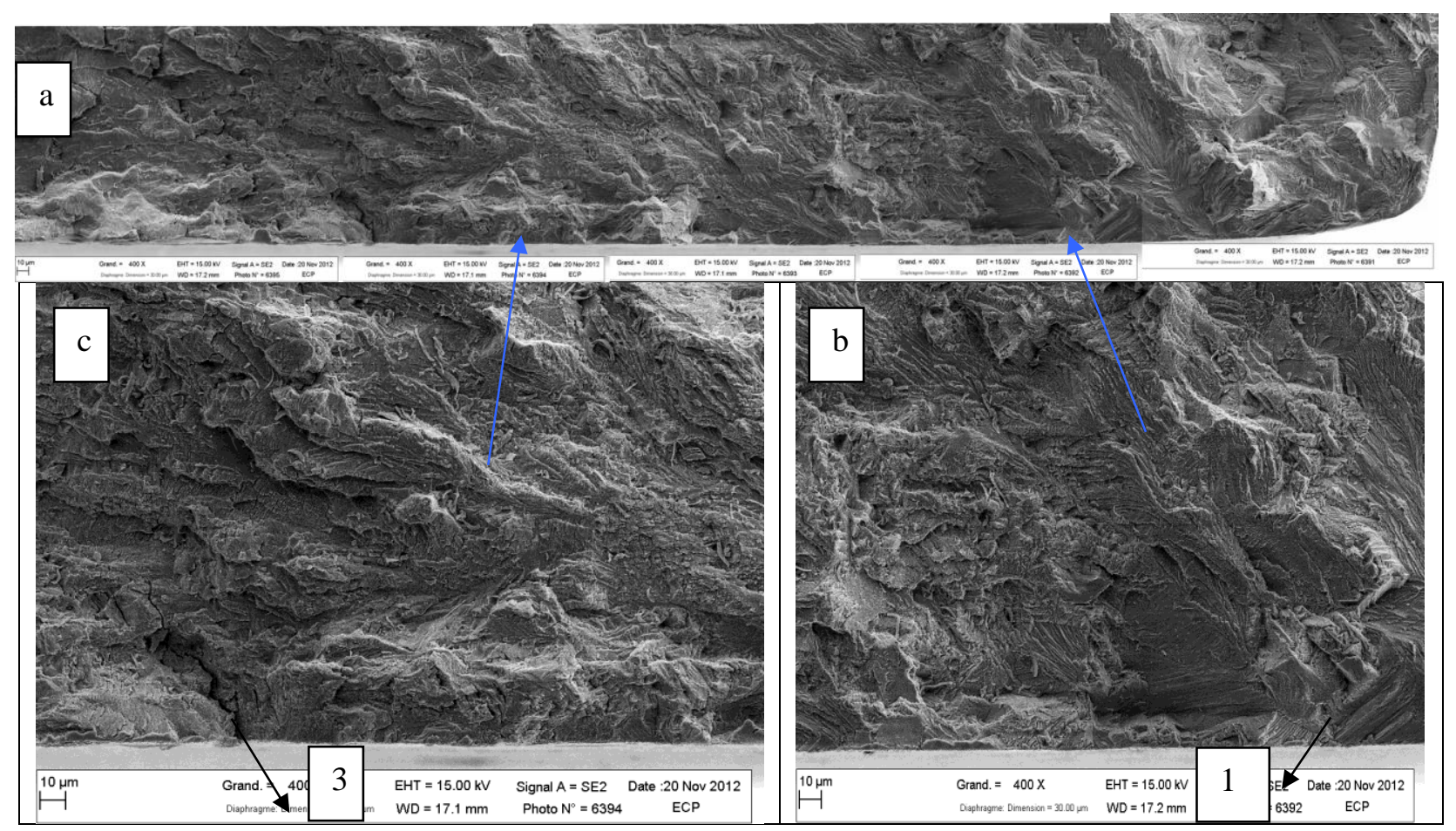

Figure 4 a)b)c): SEM observations of the fracture surface lower side (side where the temperature was achieved)

Thermal results. For this test where the temperature was monitored, the temperature profile along the specimen width was extracted for the 168 latest pictures captured by the camera (Fig. 5a), that is to say from $3.2086 .10^{7}$ cycles to $3.2153 .10^{7}$ cycles (number of the cycles at the failure). The detailed of this temperature recording has been published previously [6]. The point on the specimen surface where the temperature is maximum (red line) was measured from the corner of the crack initiation.The locations where the temperature rapidly increases were determined. They are reported on the Fig. $5 b$ (yellow lines). They are in very good relation with the fracture surface analysis.

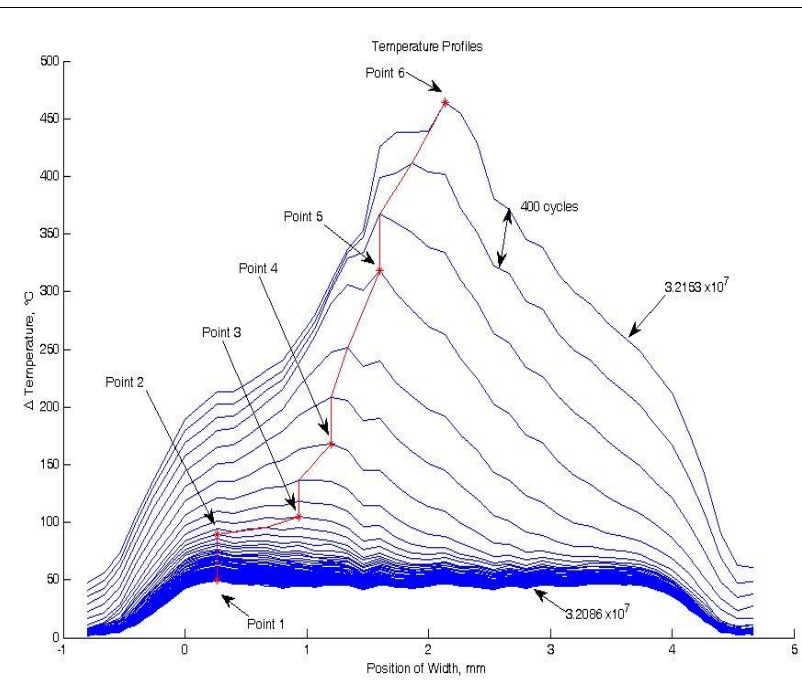

Fig. 5a: Temperature profile along the specimen width

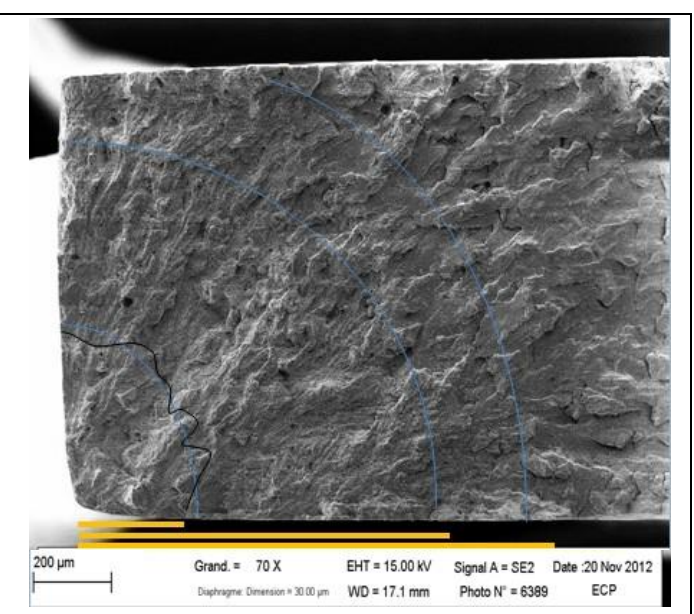

Fig. 5b Comparison between thermal results (yellow lines) and fracture surface observations

Crack propagation threshold. On the figure $5 \mathrm{~b}$, according to the all SEM observations, this transition between the stage I and the transition crack propagation zone on the fracture surface has been reported. For this Armco iron tested on flat specimens, the crack initiation site was located 
either in a corner (Fig. 6) as shown previously or on the specimen side (Fig. 7). For each specimen, the crack initiation site dimensions were determined and the stress intensity factors were calculated by the appropriated formula (Figs 6 and 7).

Assuming that for $\mathrm{R}=-1, \Delta \mathrm{K}_{\mathrm{eff}} \approx \mathrm{K}_{\mathrm{max}}$, a plot of $\Delta \mathrm{K}_{\mathrm{eff}}$ at the transition between the initiation and transition propagation stage according to the fatigue stress amplitude (Fig. 8) and number of cycles (Fig. 9) shows that this crack propagation threshold is constant and equals to $3.99 \mathrm{MPa} \sqrt{\mathrm{m}}$. Results on cylindrical specimens on this Armco iron tested at $\mathrm{R}=-1$ gives a $\Delta \mathrm{K}_{\text {eff }}$ at the transition between the initiation and propagation stage equals to $3.51 \mathrm{MPa} \sqrt{\mathrm{m}}$ (2 tests).

Table 2: Results of $\Delta \mathrm{K}_{\text {eff (initiation } \rightarrow \text { propagation) }}$

\begin{tabular}{|c|c|c|c|c|c|c|}
\hline specimen & $\begin{array}{l}\text { Stress, } \\
\sigma_{\mathbf{a}} \\
\mathrm{MPa}\end{array}$ & $\begin{array}{l}\mathrm{a}, \\
\mu \mathrm{m}\end{array}$ & $\mathbf{c}, \mu \mathrm{m}$ & $\begin{array}{l}\text { Fatigue } \\
\text { life, } \mathbf{N}_{\mathrm{f}}\end{array}$ & $\begin{array}{l}\Delta K_{\text {eff }} \text { at } \\
\text { transition } \\
\text { edge }\end{array}$ & $\mathrm{B} \longrightarrow \mathrm{b} T$ \\
\hline FF105 & 117 & 465 & 889.2 & $5.2 \mathrm{E}+07$ & 4.03 & $\frac{1}{0}$ \\
\hline FF118 & 190 & 466 & 232.4 & $3.7 \mathrm{E}+07$ & 4.12 & \multirow{5}{*}{$\begin{array}{l}\mathrm{K}_{\mathrm{I}}=\mathrm{F}_{\mathrm{c}}(\mathrm{a}, \mathrm{t}, \mathrm{c}) \sigma \sqrt{\mathrm{a}} \\
\begin{array}{c}\text { Fig.6: Crack initiation site in a } \\
\text { corner }\end{array}\end{array}$} \\
\hline FF204 & 124 & 539 & 726.9 & $5.0 \mathrm{E}+06$ & 4.21 & \\
\hline FF325 & 178 & 378 & 294.0 & $3.2 \mathrm{E}+07$ & 4.00 & \\
\hline FF330 & 176 & 259 & 537.0 & $5.2 \mathrm{E}+06$ & 4.18 & \\
\hline & & & & & & \\
\hline specimen & $\begin{array}{l}\text { Stress, } \\
\sigma_{\mathrm{a}} \\
\text { МPa }\end{array}$ & $\begin{array}{l}\mathrm{a}, \\
\mu \mathrm{m}\end{array}$ & c, $\mu \mathrm{m}$ & $\begin{array}{l}\text { Fatigue } \\
\text { life, } \mathbf{N}_{\mathrm{f}}\end{array}$ & $\begin{array}{l}\Delta K_{\text {eff }} \text { at } \\
\text { transition } \\
\text { edge }\end{array}$ & \multirow{6}{*}{$\begin{array}{c}\text { Fig.7:Crack initiation site on the } \\
\text { side }\end{array}$} \\
\hline FF108 & 107 & 551.2 & 432.93 & $1.9 \mathrm{E}+08$ & 3.93 & \\
\hline FF304 & 185 & 262.9 & 277.86 & $5.5 \mathrm{E}+06$ & 3.70 & \\
\hline FF309 & 215 & 226.8 & 246.48 & $1.6 \mathrm{E}+07$ & 4.01 & \\
\hline FF326 & 175 & 282.0 & 275.00 & $2.8 \mathrm{E}+08$ & 3.52 & \\
\hline FF301 & 222 & 376.8 & 214.08 & $5.6 \mathrm{E}+05$ & 4.30 & \\
\hline
\end{tabular}

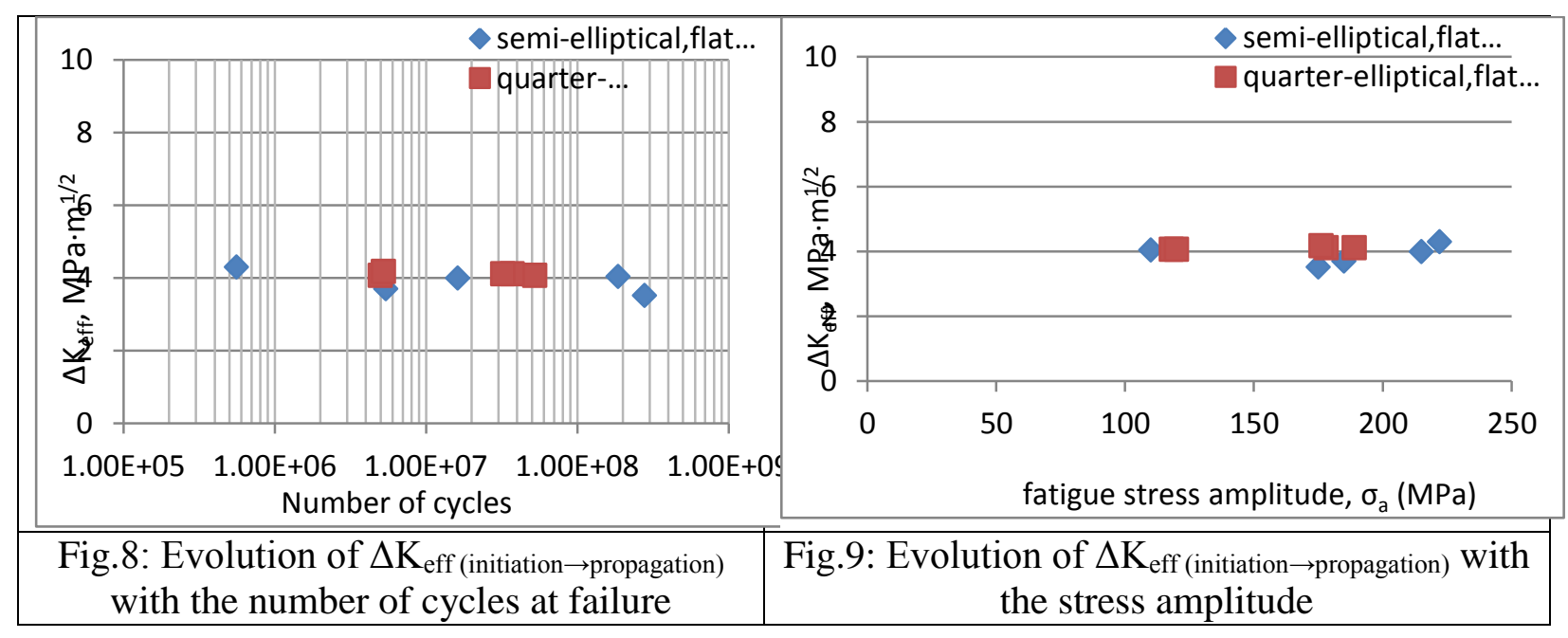

Discussion. Other results [1] on a spring steel with a martensitic microstructure $(0.38 \% \mathrm{C}, 13.5 \% \mathrm{Cr}$, $1 \% \mathrm{Mo}$ ) tested on flat specimens at $20 \mathrm{kHz}$ and $\mathrm{R}=-1$ gives a $\Delta \mathrm{K}_{\text {eff (initiation } \rightarrow \text { propagation) }}$ equals to 3.65 $\mathrm{MPa} \sqrt{\mathrm{m}}(12$ tests), and on a bearing steel with a martensitic microstructure $(1.03 \% \mathrm{C}, 1.46 \% \mathrm{Cr}$, $0.9 \% \mathrm{Mo}$ ) tested on cylindrical specimens at $20 \mathrm{kHz}$ and $\mathrm{R}=-1$ a $\Delta \mathrm{K}_{\text {eff (initiation } \rightarrow \text { propagation) }}$ equals to $4.06 \mathrm{MPa} \sqrt{\mathrm{m}}$ (8 tests). Hong [11] applying the Murakami method ( $\Delta \mathrm{K}=0.5 \Delta \sigma_{\mathrm{a}} \sqrt{ } \pi \sqrt{ }$ area) for rotating bending, founded at the periphery of the dark area (=Fine Granular Area) a lower bound of $\Delta \mathrm{K}=4 \mathrm{MPa} \sqrt{\mathrm{m}}$, and Sakai [4] a mean value of $4.84 \mathrm{MPa} \sqrt{\mathrm{m}}$. These results suggest that the $\Delta \mathrm{K}_{\text {eff }}$ at 
the transition from intiation to propagation is comprised between 3.5 and $5 \mathrm{MPa} \sqrt{\mathrm{m}}$, that is to say almost constant for steels (bcc materials) whatever the loading condition (rotating bending, pushpull or pull-pull), whatever the fracture pattern : surface (corner or side on flat specimens) or subsurface, whatever the design specimen shape (circular or flat), whatever the microstructure and mechanical properties and whatever the stress amplitude and the fatigue life.

The model of Paris et al. [6,7] for crack growth in the fish-eye is based on the integration of the Paris-Hertzberg'law. Reviews on crack growth and threshold allow to predict the threshold corner at $\mathrm{da} / \mathrm{dN}=\mathrm{b}$ and $\Delta \mathrm{K}_{\text {eff }} / \mathrm{E} \sqrt{\mathrm{b}}=1$, where $\mathrm{b}$ is the Burger's vector and $\mathrm{E}$ is elastic modulus. For steels, $\mathrm{E} \sqrt{\mathrm{b}}=3.25 \mathrm{MPa} \sqrt{\mathrm{m}}$ which is very closed to the previous results.

\section{Conclusion}

The threshold at the transition between initiation and propagation stage has been calculated from fracture surface observations in a SEM for an Armco iron for which the crack initiates on the specimen surface. The results comprised between 3.5 and $5 \mathrm{MPa} \sqrt{\mathrm{m}}$, are equivalent to previous or litterature results. It seems that this treshold is an intrinsic characteristic for the investigated steels whatever the initiation site,the tests and materials parameters. These results corroborate the threshold corner of the crack propagation rate law proposed by Herztberg and Paris $(\Delta K=E \sqrt{ })$.

Acknowledgements: This research was supported by the grant from the project of Microplasticity and energy dissipation in very high cycle Fatigue (DISFAT, project No. ANR-09-BLAN-0025-09), which funded by the National Agency of Research, France (ANR). The authors thank F.Garnier for her participation of SEM observations.

\section{References}

[1] C. Wang, PhD thesis, Microplasticité et dissipation en fatigue à très grand nombre de cycles du fer et de l'acier, Université Paris Ouest, 7 juin 2013

[2] Ngoc Lam Phung, PhD thesis, Fatigue sous très faible amplitude de contrainte: analyse des mécanismes précurseurs de l'amorçage de fissures dans le cuivre polycristallin, 10 décembre 2012

[3] Murakami, Y., (2002). The Mechanism of Fatigue Failure of Steels in the Ultralong Life Regime of $\mathrm{N}>10^{7}$ Cycles. In: Metal Fatigue : Effects of Small Defects and Non metallic Inclusions, Elsevier, Oxford, 2002,UK

[4] X. Li, T. Sakai, Q. Li, L.T. Lu, P. Wang, Reliability evaluation on very high cycle fatigue property of GCr15 bearing steel, Int Jl Fatigue 32(2010)1096-1107

[5] K. Shiozawa, Y. Morii, , S. Nishino, L. Lu, Int Jl Fatigue 2006 ; 28 :1521-1532

[6] C. Wang, D. Wagner, C. Bathias, Study of fatigue crack mechanism on an armco iron in the gigacycle fatigue by temperature recording and microstructural observations, 13th Int Conf on Fracture, juin 2013, Beijing, Chine

[7] Z. Huang, D. Wagner, C. Bathias, P.C. Paris, Subsurface Crack Initiation and Propagation Mechanism in the Gigacycle Fatigue, Acta Materiala, 58 (2010), 6046-6054

[8] Paris, P.C., Marines-Garcia I., R.W. Hertzberg, K. Donald. The Relationship of Effective Stress Intensity, Elastic Modulus and Burgers-Vector on Fatigue Crack Growth as Associated with «Fish Eye » Gigacycle Phenomena. Proc .Very High Cycle Fatigue 3, Ritsumeikan University, Kusatsu, Japan, 2004.

[9] C. Wang, D. Wagner, Q.Y. Wang, C. Bathias - Gigacycle fatigue initiation mechanism in Armco iron, Int Jl Fatigue, Vol 45(2012)91-97

[10] C. Wang, D. Wagner, C. Bathias, Fatigue crack initiated from PSB at VHCF in Iron, 13th Int Conf on Fracture, juin 2013, Beijing, Chine

[11] Y. Hong, Z. Lei, C. Sun, A. Zhao, Characteristics of crack interior initiation and early growth originated from inclusion for very high cycle fatigue of high strength steels, CP 2012, Gaeta, Italy 